\title{
Biocatalytic preparation and absolute configuration of enantiomerically pure fungistatic anti-2-benzylindane derivatives. Study of the detoxification mechanism by Botrytis cinerea
}

\author{
Cristina Pinedo-Rivilla, ${ }^{a}{ }^{\text {Josefina Aleu, }}{ }^{a}$ Manuel Grande Benito ${ }^{b}$ and Isidro G. Collado ${ }^{* a}$ \\ Received 9th March 2010, Accepted 3rd June 2010 \\ First published as an Advance Article on the web 23rd June 2010 \\ DOI: 10.1039/c003938a
}

Enantiomerically pure 2-benzylindane derivatives were prepared using biocatalytic methods and their absolute configuration determined. $(1 R, 2 S)$-2-Benzylindan-1-ol $((1 R, 2 S)-2)$ and

$(S)$-2-benzylindan-1-one $((S)$-3) were produced by fermenting baker's yeast. Lipase-mediated esterifications and hydrolysis of the corresponding racemic substrates gave rise to the enantiopure compounds $(1 S, 2 R)$-2-benzylindan-1-ol $((1 S, 2 R)-2)$ and $(1 R, 2 S)$-2-benzylindan-1-ol $((1 R, 2 S)-2)$, respectively. The antifungal activity of these products against two strains of the plant pathogen Botrytis cinerea was tested. The metabolism of anti-( \pm )-2-benzylindan-1-ol (anti-( \pm )-2) by B. cinerea as part of the fungal detoxification mechanism is also described and revealed interesting differences in the genome of both strains.

\section{Introduction}

The Botrytis species belong to the most geographically widespread group of plant pathogens and saprophytes. ${ }^{1}$ Grey mould, a grapevine disease caused by the fungus Botrytis cinerea results in crop losses and low quality wines from infected grapevines affecting many wine-producing countries. ${ }^{2}$

Because the fungus develops a rapid tolerance to commercial fungicides, these compounds must be used in increasingly higher quantities. This in turn leads to the emergence of highly resistant strains in Botrytis cinerea populations while also polluting both soil and water. Consequently, there is interest in the development of novel antifungal agents that are active against this organism.

We screened compounds analogous to various phytoalexins ${ }^{3}$ with a view to finding substrates with antifungal properties against this fungus and were successful in identifying several different benzylindane derivatives which exhibited strong fungicidal activity against $B$. cinerea.

The preparation of optically active forms of benzylindane derivatives is not only interesting in terms of their antifungal properties but also because they could serve as synthetic precursors to other natural products playing an important role in the development of pharmaceuticals and for medicinal chemistry. ${ }^{4}$ Thus, based on previous results, ${ }^{5}$ we selected biocatalytic methods to pursue enantiomerically pure forms of benzylindane derivatives from the ketone $(E)$-2-benzylideneindan-1-one (1) in order to compare their antifungal activities.

Since several phytopathogenic fungi have been reported to detoxify phytoalexins, ${ }^{6}$ producing less toxic degradation products than the parent compounds, ${ }^{7}$ we decided to study the biotrans-

aDepartamento de Química Orgánica, Facultad de Ciencias, Universidad de Cádiz, República Saharaui s/n, Apdo. 40, 11510 Puerto Real, Cádiz, Spain. E-mail: isidro.gonzalez@uca.es; Fax: +34-956-016193; Tel: +34956-016368

${ }^{b}$ Departamento de Química Orgánica, Facultad de Ciencias Químicas, Universidad de Salamanca, E-37008 Salamanca, Spain formation of anti-( \pm )-2-benzylindan-1-ol (anti-( \pm )-2), which had shown the highest antifungal activity in previous studies, using $B$. cinerea as a part of the fungal detoxification mechanism.

\section{Results and discussion}

\section{Baker's yeast reduction}

Based on previous results ${ }^{8}$ and the well known ability of baker's yeast to reduce a high number of ketones into optically active alcohols, ${ }^{9}$ we decided to employ a baker's yeast-mediated approach to enantiopure alcohol derivatives using the corresponding ketone (E)-2-benzylideneindan-1-one (1) as substrate. The results are shown in Table 1. The diastereomeric ratio and enantiomeric excesses were determined by HPLC analysis using a Chiralcel OD column.

Table 1 Results of baker's yeast-mediated reduction

\begin{tabular}{|c|c|c|c|c|c|c|c|}
\hline \multirow[b]{2}{*}{$\begin{array}{l}\text { Allyl alcohol } \\
(\mathrm{mM})\end{array}$} & \multirow[b]{2}{*}{$\begin{array}{l}\text { Hexane } \\
(\%)\end{array}$} & \multicolumn{3}{|c|}{$(1 R, 2 S)-2$} & \multicolumn{2}{|l|}{$(S)-\mathbf{3}$} & \multirow[b]{2}{*}{$\begin{array}{l}\text { Time } \\
\text { (h) }\end{array}$} \\
\hline & & $\begin{array}{l}\text { Conv. }{ }^{a} \\
(\%)\end{array}$ & $e e(\%)$ & $e d(\%)$ & $\begin{array}{l}\text { Conv. }{ }^{a} \\
(\%)\end{array}$ & $e e(\%)$ & \\
\hline - & - & 0.24 & 89 & 96 & 9 & 52 & 48 \\
\hline - & - & 0.5 & 36 & 94 & 16 & 13 & 240 \\
\hline 67 & 1.2 & 2.0 & 74 & 97 & - & - & 96 \\
\hline
\end{tabular}

${ }^{a}$ Conv.: Conversion is the $\%$ of product in the recovered material.

As shown in Table 1, after the incubation of $\mathbf{1}$ in fermenting baker's yeast following the conventional procedure (see Experimental section), two transformation products were isolated, $(S)$ (+)-2-benzylindan-1-one $((S)-3)\left(52 \% e e,[\alpha]_{\mathrm{D}}^{20}+162(c \quad 0.1\right.$ in $\left.\mathrm{CHCl}_{3}\right)$ ) and $(1 R, 2 S)-(+)-2$-benzylindan-1-ol $(1 R, 2 S)-2(89 \%$ ee, $96 \%$ ed, $[\alpha]_{\mathrm{D}}^{20}+6.8\left(c 1\right.$ in $\left.\left.\mathrm{CHCl}_{3}\right)\right)($ Scheme 1$)$. The spectroscopic data of these products corresponded to those found in the literature. ${ }^{8,10}$ The $e d$ was very high for alcohol $\mathbf{2}$ in all the cases $(>94 \%)$. The absolute configuration of $(1 R, 2 S)-\mathbf{2}$ was determined by means of circular dichroism. 
Table 2 Results of lipase-mediated acetylation of anti-( \pm )-2-benzylindan-1-ol (anti-( \pm )-2)

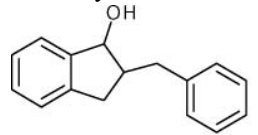

an $t i-( \pm)-2$

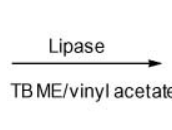

TBME/vinyl aceta

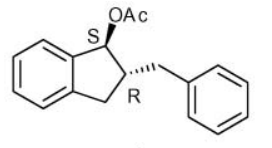

$(1 S, 2 R)-4$

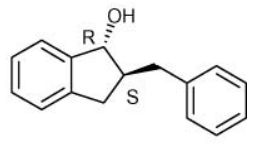

$(1 R, 2 S)-2$

\begin{tabular}{|c|c|c|c|c|c|c|c|c|}
\hline Enzyme & Vinyl acetate (eq) & Time/h & Yield $^{a}$ of $(1 S, 2 R)-4(\%)$ & ee of $(1 S, 2 R)-4(\%)$ & Yield ${ }^{a}$ of $(1 R, 2 S)-2(\%)$ & $e e$ of $(1 R, 2 S)-\mathbf{2}(\%)$ & Conv. ${ }^{b}(\%)$ & E \\
\hline CRL & 10 & 67 & 8 & $>99$ & 92 & $>99$ & 50 & $>400$ \\
\hline PS & 1 & 43 & 12 & $>99$ & 91 & $>99$ & 50 & $>400$ \\
\hline PS & 1 & 160 & 67 & $>99$ & 51 & $>99$ & 50 & $>400$ \\
\hline
\end{tabular}

${ }^{a}$ Yield $100 \%$ at $50 \%$ conversion after hydrolysis of the acetate derivative. ${ }^{b}$ Conv.: conversion.

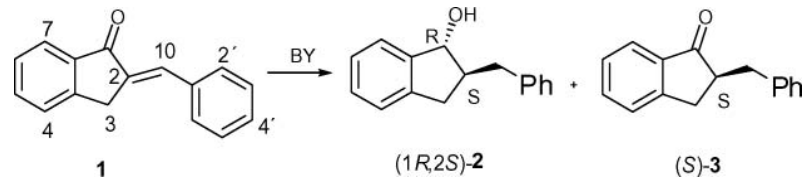

Scheme 1 Biological reduction of (E)-2-benzylideneindan-1-one (1).

The circular dichroism curves of alcohol 2 show two positive Cotton effects $(\mathrm{CE})$ related to the ${ }^{1} \mathrm{~L}_{\mathrm{b}}\left(\Delta \varepsilon_{272}+0.22\right)$ and ${ }^{1} \mathrm{~L}_{\mathrm{a}}\left(\Delta \varepsilon_{221}\right.$ $+1.5)$ bands. The low intensity of these bands rules out an exciton coupling between both aromatic rings so the CE should be caused by the benzylic chiral center. According to the benzene sector rules $^{11}$ applied to the most stable conformation of the indanol (equatorial $-\mathrm{OH}$ and $-\mathrm{CH}_{2} \mathrm{Ph}$ groups), a positive $\mathrm{CE}$ of the ${ }^{1} \mathrm{~L}_{\mathrm{b}}$ band agrees with the $1 R$ configuration. In addition, the CD spectrum of $\mathbf{2}$ is quite similar to the mirror CD curve published for $S$-indan-1-ol. ${ }^{12}$

The absolute configuration of $(S)$-3 was determined from oxidation of the alcohol $(1 R, 2 S)$-2 whose absolute configuration was known, and by comparing their optical values.

It has been reported that inhibition of certain type of enzymes in the baker's yeast reaction may control the enantioselectivity of the reduction. ${ }^{13}$ We therefore tried to inhibit the reducing enzymes selectively by adding inhibitors such as allyl alcohol and a small amount of organic solvent ${ }^{14}$ to dissolve the substrate (see Table 1) in order to improve the transformation. The addition of allyl alcohol and hexane improved the stereoselectivity and conversion of the alcohol $(1 R, 2 S)-(+)-2-$ benzylindan-1-ol $((1 R, 2 S)-2)(97 \% \mathrm{ed}$, $[\alpha]_{\mathrm{D}}^{20}+6.5\left(c 0.1\right.$ in $\left.\left.\mathrm{CHCl}_{3}\right)\right)$ but ee was diminished $(74 \% e e)$. Ketone 3 was not isolated from the broth containing the additives.

\section{Lipase-mediated transformations}

We focused on the kinetic resolution of the racemic secondary alcohols and acetates, obtained as described in the experimental section to explore new methods for the preparation of enantiomerically pure alcohols from ketone $\mathbf{1}$. Lipases are versatile biocatalysts acting with high efficiency in acylation or hydrolysis. ${ }^{5,15}$

\section{Lipase-mediated acetylations}

The racemic secondary alcohol anti- $( \pm)-2$ prepared by reacting the ketone 1 with $\mathrm{LiAlH}_{4}$ was added to different media with vinyl acetate as an acyl donor and tert-butyl methyl ether (TBME) as the organic solvent and three different lipases: lipase PS (from
Pseudomonas cepacia), PPL (porcine pancreas lipase) and CRL (Candida rugosa lipase). The results are summarised in Table 2. The lipase PS appeared to be more efficient in the enzymatic acetylation of these substrates producing the highest enantioselectivities and yields while lipase PPL showed no enantioselection.

Different reaction times and vinyl acetate concentrations (1 and 10 eq) were tested in an attempt to increase the conversion rate (Table 2). Enantiomeric excesses were very high in all the cases (>99\%).

The best result for enantiomer ( $1 S, 2 R)-4$ was with lipase PS yielding $67 \%$ acetate derivative. Following hydrolysis of the acetate derivative with potassium hydroxide in methanol, the enantiopure alcohol was identified as $(1 S, 2 R)$-2-benzylindan-1-ol $((1 S, 2 R)-2)$ which was obtained with a high ee $>99 \%\left([\alpha]_{\mathrm{D}}^{20}-11.6(c \quad 0.1\right.$ in $\left.\mathrm{CHCl}_{3}\right)$ ) and a conversion of $50 \%$, using 1 eq of vinyl acetate as the acyl donor.

The best result for the enantiomer (1R,2S)-2-benzylindan-1-ol $((1 R, 2 S)-2)$ was with lipase CRL yielding $92 \%$, ee $>99 \%\left([\alpha]_{\mathrm{D}}^{20}\right.$ $+11.8\left(c 0.1\right.$ in $\left.\mathrm{CHCl}_{3}\right)$ ) and a conversion of $50 \%$, using 10 eq of vinyl acetate as the acyl donor.

\section{Lipase-mediated hydrolysis}

Here we report on the enzyme mediated enantioselective hydrolysis of anti-( \pm )-2-benzylindan-1-yl acetate (anti-( \pm$)-4)$. Of the enzymes screened only CRL displayed high selectivity.

The racemic acetate derivative was prepared by adding the corresponding alcohol to a solution of acetic anhydride in dichloromethane-methanol $(1: 1)$. The acetate was then transformed by lipases dissolved in a mixture of 1,4-dioxane and different concentrations of buffer solution. The results of the enzymatic hydrolysis are summarized in Table 3.

In this case, the enzymatic-mediated hydrolysis afforded $(1 R, 2 S)$-2-benzylindan-1-ol $((1 R, 2 S)$-2) at a yield of $30 \%, 93 \%$

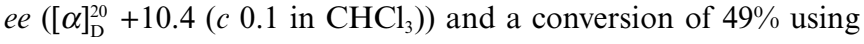
lipase CRL with a mixture of 1,4-dioxane and buffer 30\%. We were unable to obtain a high yield which could be due to the low solubility of the starting material meaning that there would be less substrate available for the lipase reaction.

\section{Antifungal assays}

The antifungal properties of all the compounds obtained in this work were determined based on their ability to inhibit 
Table 3 Results of lipase-mediated hydrolysis of anti-( \pm )-2-benzylindan-1-yl acetate (anti- $( \pm)-4)$

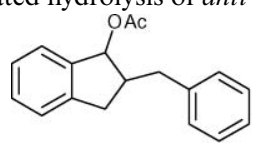

anti-( \pm - -4

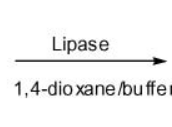

1,4-dioxane/buffer

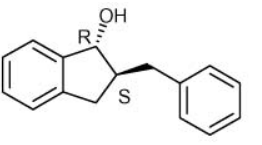

$(1 R, 2 S)-2$

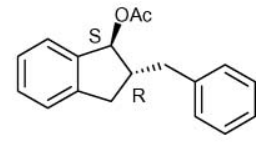

$(1 S, 2 R)-4$

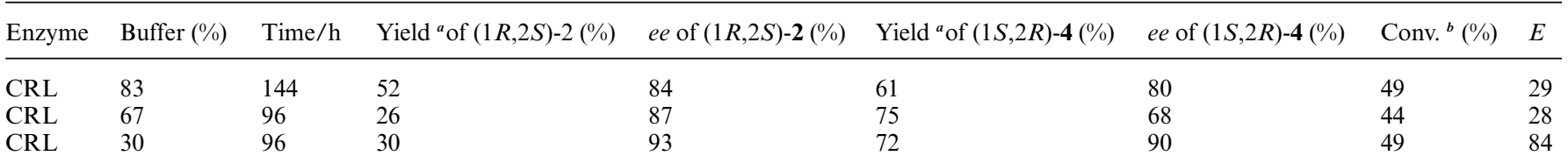

${ }^{a}$ Yield $100 \%$ at $50 \%$ conversion after hydrolysis of the acetate derivative. ${ }^{b}$ Conv.: conversion.

Table 4 Results of conidial germination bioassays of 2benzylideneindan-1-one (1)

\begin{tabular}{lllll}
\hline Compound & $\%$ of inhibition $\pm \mathrm{SD}^{a}$ & & & \\
\hline [ppm] & 100 & 50 & 25 & 12.5 \\
$B c \mathrm{UCA} 992$ & 0 & 0 & 0 & 0 \\
$B c 2100$ & 100 & 100 & 100 & 100
\end{tabular}

a \% of inhibition using PDB medium as control. Each value is the percentage of the media of three experiments \pm standard deviation.

Table 5 Results of conidial germination bioassays of (1R,2S)-(+)-2 and $((1 S, 2 R)-(-)-2$

\begin{tabular}{lllllllll}
\hline & \multicolumn{3}{l}{$\%$ of inhibition $\pm \mathrm{SD}^{a}$} \\
\cline { 2 - 7 } Compound & $(1 R, 2 S)-(+)-2$ & & \\
\hline [ppm] & 100 & 50 & 25 & 12.5 & 100 & 50 & 25 & 12.5 \\
$B c \mathrm{UCA} 992$ & 100 & $94 \pm 1$ & $34 \pm 2$ & $17 \pm 3$ & 100 & 100 & $84 \pm 1$ & $19 \pm 2$ \\
$B c 2100$ & 100 & 100 & 100 & 100 & 100 & 100 & 100 & 100 \\
a $\%$ of inhibition using PDB medium as control. Each value is the \\
percentage of the media of three experiments \pm standard deviation.
\end{tabular}

the growth of the two different strains of $B$. cinerea, $B c 2100$ and $B c$ UCA992, using the conidial germination assay. ${ }^{16}$ In general, compounds $(E)$-2-benzylideneindan-1-one (1) and anti2-benzylindan-1-ol $((1 R, 2 S)-(+)-2$ and $(1 S, 2 R)-(-)-2)$ were the most active products against both strains of $B$. cinerea. The alcohol $(1 S, 2 R)-(-)-2$ exhibited a more pronounced antifungal effect. The results of the antifungal assays for these compounds are summarized in Tables 4 and 5 .

Ketone $\mathbf{1}$ and alcohols $\mathbf{2}$ at all concentrations, even at $12.5 \mathrm{ppm}$, completely inhibited the germination (100\%) of B. cinerea 2100 .

Ketone 1 was completely inactive against $B$. cinerea UCA992 but when treated with anti-2-benzylindan-1-ol $((1 R, 2 S)-(+)-2$ and $(1 S, 2 R)-(-)-2)$, conidia and germlings of $B$. cinerea UCA992 germinated and grew to produce stunted, distorted, and abnormally branched germlings. Compound (1S,2R)-(-)-2-benzylindan-1-ol $((1 S, 2 R)-2)$ was the most active against $B$. cinerea UCA992. To confirm the results three independent experiments were carried out.

It is worth noting that acetyl derivatives $\mathbf{4}$ were inactive for both strains, indicating that the hydroxyl group plays an important role in the inhibitory mechanism.

\section{Detoxification of anti-( \pm )-2-benzylindan-1-ol (anti- $( \pm)-2)$ by} Botrytis cinerea 2100 and UCA992

The biotransformation of racemic alcohol anti- $( \pm)-2$ by $B c$ UCA992 and $B c 2100$ was studied to identify fungal detoxification mechanisms and differences in their enzymatic potential to degrade xenobiotic substrates.

Biotransformation was done in surface cultures using Roux bottles for five days after which the mycelium was filtered, extracted with ethyl acetate and the extract dried over anhydrous sodium sulfate. Purification of the dry organic extract afforded several compounds (see Scheme 2).
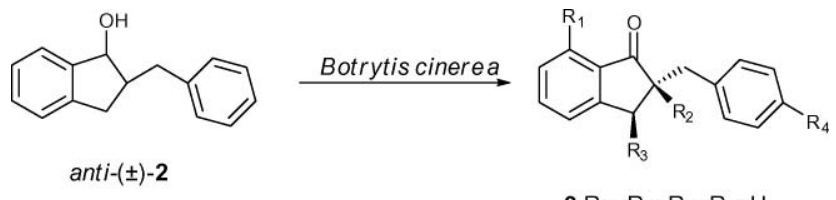

$$
\begin{aligned}
& 3 \mathrm{R}_{1}=\mathrm{R}_{2}=\mathrm{R}_{3}=\mathrm{R}_{4}=\mathrm{H} \\
& 5 \mathrm{R}_{1}=\mathrm{R}_{4}=\mathrm{H}, \mathrm{R}_{2}=\mathrm{R}_{3}=\mathrm{OH} \\
& 6 \mathrm{R}_{1}=\mathrm{R}_{2}=\mathrm{R}_{4}=\mathrm{H}, \mathrm{R}_{3}=\mathrm{OH}
\end{aligned}
$$$$
7 \mathrm{R}_{1}=\mathrm{R}_{4}=\mathrm{OH}, \mathrm{R}_{2}=\mathrm{R}_{3}=\mathrm{H}
$$

Scheme 2 Biotransformation products of anti-( \pm -2-benzylindan-1-ol (anti-( \pm )-2) by Botrytis cinerea.

In addition to the starting material, the biotransformation of anti-( \pm )-2-benzylindan-1-ol (anti-( \pm )-2) by BcUCA992 afforded the following compounds: syn-2-benzyl-2,3-dihydroxyindan-1one (5), anti-2-benzyl-3-hydroxyindan-1-one (6), and $(R)-2-(p-$ hydroxybenzyl)-7-hydroxyindan-1-one (7). The starting material recovered exhibited $[\alpha]_{\mathrm{D}}^{20}-3.5(c) 2.3$ in $\left.\mathrm{CHCl}_{3}\right)$ with $25 \% e e$, in favour of the configuration $(1 S, 2 R)$.

On the other hand, anti-( \pm -2-benzylindan-1-ol (anti-( \pm$)-2)$ was incubated at a lower concentration (50 ppm) on surface cultures of $B c 2100$ producing only one biotransformation product, $(R)$ (-)-2-benzylindan-1-one $((R)-3)$ at a yield of $60 \%$ and $75 \%$ ee. The higher potential of the strain $B c \mathrm{UCA} 992$ to biotransform anti- $( \pm)$ 2-benzylindan-1-ol (anti-( \pm )-2) is in accordance with those results obtained from antifungal assays. So, the antifungal assays and results obtained from biotransformation reveal genetic differences between both strains that could be associated with their adaptive lifestyles and their different host ranges. The strain $B c \mathrm{UCA} 992$, a wild strain isolated from a vineyard in 1992, seems to have genes which codify for oxidases involved in the detoxification of (anti$( \pm)-2)$, which would not be present in the genome of strain $B c 2100$. 
These data clearly reveal adaptive resources for the wild strain with respect to strain $B c 2100$ from CECT lab collection.

Compound $\mathbf{5}$ was isolated as a colourless oil with the molecular formula $\mathrm{C}_{16} \mathrm{H}_{14} \mathrm{O}_{3}$, determined from its HRMS and corroborated by ${ }^{13} \mathrm{C}$ NMR data. The ${ }^{1} \mathrm{H}$ NMR and ${ }^{13} \mathrm{C}$ NMR spectra were close to that of 2-benzylindan-1-one (3), but the appearance of a signal at 4.81 and $77.1 \mathrm{ppm}$ (H-3 and C-3, respectively) indicated the presence of a secondary hydroxyl group. Another signal at $77.1 \mathrm{ppm}$ in the ${ }^{13} \mathrm{C}$ NMR spectrum $(\mathrm{C}-2)$ showed that $\mathbf{5}$ was a diol derivative. The stereochemistry of both chiral carbons was determined by nOe experiments, which showed an enhancement for the signal corresponding to $\mathrm{H}-10$ when the signal assigned to $\mathrm{H}$ 3 was irradiated. Compound syn-2-benzyl-2,3-dihydroxyindan-1one (5) is reported here for the first time. The stereoselectivity of the compound $\mathbf{5}$ was very high, giving only one diastereoisomer but in the absence of at least one enantiomer of known configuration, we had no way of determining which enantiomer was which.

Spectroscopic data of compound $\mathbf{6}$ coincided with those found in the literature. ${ }^{4}$ That compound was obtained as a mixture of diastereoisomers $78: 22$ in favour of the anti-configuration and $61 \%$ ee.

Compound 7 was isolated as a yellow oil, with an $\mathrm{M}^{+}$peak at $m / z 254$ and gave rise to a ${ }^{13} \mathrm{C} \mathrm{NMR}$ spectrum consistent with the molecular formula $\mathrm{C}_{16} \mathrm{H}_{14} \mathrm{O}_{3}$. The ${ }^{1} \mathrm{H}$ NMR and ${ }^{13} \mathrm{C} \mathrm{NMR}$ spectra showed that it retained the benzylindanone skeleton, but the appearance of two signals at 156.9 and $158.5 \mathrm{ppm}$ in its ${ }^{13} \mathrm{C}$ NMR spectrum (C-4' and C-7, respectively) indicated two hydroxylations on the aromatic rings, according to the product 2( $p$-hydroxybenzyl)-7-hydroxyindan-1-one (7). Furthermore, structure 7 was supported by homo- and heteronuclear-2D-correlation experiments. Its absolute configuration was determined by comparison of its specific rotation value $\left([\alpha]_{\mathrm{D}}^{20}-27.6,81 \% e e\right)$ with that of $(R)$-2-benzylindan-1-one $((R)-3)\left([\alpha]_{\mathrm{D}}^{20}-211.2,75 \% e e\right)$, whose absolute configuration was known. Both compounds presented a negative value, indicating the same configuration on the C-2. Compound ( $R$ )-2-( $p$-hydroxybenzyl)-7-hydroxyindan-1-one (7) is reported here for the first time.

The antifungal activity of the detoxification products against $B$. cinerea was also studied using the 'inhibition of conidial germination' technique. These products have been shown to be less toxic to fungal growth than anti-( \pm )-2-benzylindan-1-ol (anti$( \pm)-2)$ thus confirming that $B$. cinerea has a mechanism to detoxify compound anti- $( \pm)-\mathbf{2}$ by hydroxylating several positions.

\section{Conclusions}

The economic problems arising from phytopathogen fungi make the rational control of these diseases a very interesting focus of organic chemistry. Moreover, biocatalysis shows high regioand stereo-specificity in nature under mild and environmentally friendly reaction conditions. In this work we have reported how new antifungal compounds were obtained by means of biocatalytic methods based on the use of baker's yeast and enzymes which could actually be re-used thanks to their remarkable stability and biodegradability.

The studies described above demonstrate the biocatalytic potential of the lipases in obtaining enantiomerically pure $(1 R, 2 S)$ and (1S,2R)-2-benzylindan-1-ol (2) which have proven to be highly active against Botrytis cinerea.
Based on these results we also studied the biotransformation of anti-( \pm )-2-benzylindan-1-ol (anti-( \pm$)-2)$ by B. cinerea as part of the fungal detoxification mechanism. Biotransformation products have been shown to be less toxic to fungal growth than anti-(土)-2. The different behaviour of both strains indicates that the enzymatic system of $B c 2100$ is not able to detoxify totally the compound anti-( \pm -2, which produces a total inhibition on the fungus. These data reveal significant differences in the genome of these strains, specially in genes which would codify for the oxidases involved in the detoxification mechanism of 2 .

\section{Experimental}

\section{General experimental procedures}

Optical rotations were determined with a Perkin-Elmer 241 polarimeter. IR spectra were recorded on a Mattson Genesis spectrophotometer, series FTIR. ${ }^{1} \mathrm{H}$ and ${ }^{13} \mathrm{C}$ NMR measurements were obtained on Varian Unity 400 and Varian Unity 600 NMR spectrometers with $\mathrm{SiMe}_{4}$ as the internal reference. Mass spectra were recorded on a GC-MS Thermoquest spectrometer (model: Voyager), and a VG Autospec-Q spectrometer. HPLC was performed with a Hitachi/Merck L-6270 apparatus equipped with a UV-VIS detector (L 6200) and a differential refractometer detector (RI-71). CD spectra were recorded on a Jobin-Ybon Mark III Dichrograph in ethanol as solvent. TLC was performed on Merck Kiesegel $60 \mathrm{~F}_{254}, 0.2 \mathrm{~mm}$ thick. Silica gel (Merck) was used for column chromatography. Purification by means of HPLC was accomplished with a silica gel column (Hibar 60, $7 \mathrm{~m}, 1 \mathrm{~cm}$ wide, $25 \mathrm{~cm}$ long). Chemicals were products of Fluka or Aldrich. All solvents used were freshly distilled. Baker's yeast was obtained from a local store. The following enzymes were used in this work: Candida rugosa Lipase (Sigma, Type VII, $950 \mathrm{U} \mathrm{mg}^{-1}$ ), Pseudomonas cepacia Lipase (Amano Pharmaceuticals Co., Japan) and Porcine Pancreas Lipase (Sigma, Type II).

\section{General procedure for baker's yeast transformation}

A mixture composed of baker's yeast (250 g), D-glucose (100 g), and tap water $(1 \mathrm{~L})$ was stirred in a $2 \mathrm{~L}$ beaker at $50{ }^{\circ} \mathrm{C}$ for $30 \mathrm{~min}$. Substrate 1 ( $5.93 \mathrm{mmol}$ ), which had been dissolved in a minimum amount of ethanol, was then added dropwise. At the end of the reaction period $1 \mathrm{~L}$ of ethyl acetate was added and the crude reaction mixture was filtered through a large Büchner funnel on a Celite pad which was later washed with the same solvent. The aqueous phase was extracted twice with $0.5 \mathrm{~L}$ of ethyl acetate, the organic phase was dried over $\mathrm{Na}_{2} \mathrm{SO}_{4}$ and the solvent was then evaporated under reduced pressure to dryness. The residue obtained was purified by means of column chromatography.

Baker's yeast transformation in the presence of several additives. A mixture of baker's yeast $(250 \mathrm{~g})$, water (1 L), and D-glucose $(100 \mathrm{~g}, 0.505 \mathrm{~mol})$ was stirred at $50{ }^{\circ} \mathrm{C}$ for $30 \mathrm{~min}$. The substrate $1(5.93 \mathrm{mmol})$ was dissolved in allyl alcohol $(8 \mathrm{~mL}, 67 \mathrm{mmol})$ and hexane $(12 \mathrm{~mL}, 1.2 \%)$ and was then added dropwise to the mixture. The reaction was then stirred for a further period of time. The work-up procedure was essentially the same as that described above. The results are shown in Table 1. 


\section{Chemical transformations}

Synthesis of racemic substrates. Reduction of $(E)-2$ benzylideneindan-1-one ${ }^{10}$ (1) (5 g, 0.02 mol) with $\mathrm{LiAlH}_{4}(8 \mathrm{~g}, 0.2$ $\mathrm{mol}$ ) in $10 \mathrm{~mL}$ dry $\mathrm{THF}$ at room temperature in $\mathrm{N}_{2}$ atmosphere gave anti-( \pm )-2-benzylindan-1-ol (anti-( \pm )-2) (4.2 g, 82.5\%, 100\% $e d)$. The ${ }^{1} \mathrm{H}$ NMR data of this product coincided with those found in the literature. ${ }^{8,10} \mathrm{HPLC}$ (n-hexane/ $i-\mathrm{PrOH} 9: 1,0.6 \mathrm{~mL} \mathrm{~min}^{-1}$ ): $t_{\mathrm{R}} 14 \min (S, R)$ and $30 \min (R, S)$.

After purification, compound anti- $( \pm)-2(0.1 \mathrm{~g}, 0.44 \mathrm{mmol})$ was dissolved in dry pyridine and acetic anhydride $(50 \mathrm{~mL})$ was added dropwise. The reaction mixture was stirred for $20 \mathrm{~h}$. The solvent was then removed and the crude reaction product chromatographed to give anti-( \pm )-2-benzylindan-1-yl acetate (anti- $( \pm)$ 4) $(84.5 \%)$, obtained as a white solid; $\delta_{\mathrm{H}}\left(400 \mathrm{MHz} ; \mathrm{CDCl}_{3}\right) 2.00$ (3 H, s, H-11), 2.65 (1 H, dd, $J 6.4$ and 16.0, H-3a), 2.71 (1 H, dd, $J 9.1$ and 12.9, H-10a), 2.78 (1 H, m, H-2), 2.98 (1 H, dd, $J 6.1$ and 12.9, H-10b), 3.10 (1 H, dd, $J 7.6$ and 16.0, H-3b), 6.08 (1 H, d, $J$ 5.0, H-1), 7.21 (4 H, dd, 4Harom), 7.25 (3 H, m, 3Harom), 7.29 (2 $\mathrm{H}, \mathrm{d}, 2$ Harom); $\delta_{\mathrm{C}}\left(100 \mathrm{MHz} ; \mathrm{CDCl}_{3}\right) 21.1$ (q, C-11), 35.7 (d, C-3), 39.1 (d, C-10), 47.4 (d, C-2), 82.1 (d, C-1), 124.9 (d, Carom), 125.4 (d, Carom), 126.1 (d, Carom), 126.8 (d, Carom), 128.4 (d, Carom), 128.8 (d, 2Carom), 128.9 (d, 2Carom), 140 (d, Carom), 140.7 (s, C8), 142.8 (s, C-9), 189.4 (CO). MS ( $m / z, \%) 206\left(\mathrm{M}^{+}-60,92\right), 115$ (78), 91 (100), 77 (26), 43 (61). HPLC (n-hexane/ $i$-PrOH 95 : 5 , $\left.0.7 \mathrm{~mL} \mathrm{~min}^{-1}\right): t_{\mathrm{R}} 12 \min (S, R)$ and $17 \min (R, S)$.

Oxidation of $(1 R, 2 S)-(+)-2-b e n z y l i n d a n-1-o l ~(1 R, 2 S)-2$. The alcohol $(1 R, 2 S)-(+)-2-$ benzylindan-1-ol $((1 R, 2 S)-2)(5 \mathrm{mg}, 0.022$ mmol) was oxidised with manganese(IV) oxide (1.5 eq) in methylene chloride solution $(1.5 \mathrm{~mL})$ at room temperature. After purification on a silica gel column, eluting with hexane-ethyl acetate $(9: 1)$, the derivative $(S)-(+)-2$-benzylindan-1-one $((S)-3)$ (98\% yield) was afforded.

\section{Lipase-mediated reactions}

Lipase-mediated acetylations. A mixture of the racemic alcohol anti-( \pm )-2 (51 mg, $0.23 \mathrm{mmol})$, lipase $(51 \mathrm{mg})$, and vinyl acetate $(0.23 \mathrm{mmol}$ or $2.3 \mathrm{mmol})$ in tert-butyl methyl ether $(2 \mathrm{~mL})$ was stirred at room temperature. The residue obtained upon evaporation of the filtered reaction mixture was chromatographed on a silica gel column and eluted with hexane-ethyl acetate $(95: 5)$. The first eluted fractions provided the acetate derivative $(1 S, 2 R)-4\left([\alpha]_{\mathrm{D}}^{20}-89(c) 0.2\right.$ in $\left.\mathrm{CHCl}_{3}\right),>99 \%$ ee $)$ and the last eluted fractions afforded the unreacted starting material $(1 R, 2 S)$ (+)-2-benzylindan-1-ol $((1 R, 2 S)-2),[\alpha]_{\mathrm{D}}^{20}+11.8\left(c 0.1\right.$ in $\left.\mathrm{CHCl}_{3}\right)$, $e e>99 \%, \Delta \varepsilon_{272}+0.22 ; \Delta \varepsilon_{221}+1.5\left(c 7.7 \times 10^{-3} \mathrm{M}\right.$ in EtOH $)$. Detailed results of the enzyme-mediated acetylations are reported in Table 2.

Treatment of acetate derivative (1S,2R)-4 (5 mg, $0.02 \mathrm{mmol})$ with $\mathrm{KOH}(2 \mathrm{mg}, 0.04 \mathrm{mmol})$ in methanol solution at room temperature for $2 \mathrm{~h}$ afforded $3.8 \mathrm{mg}(90.2 \%)$ of the compound $(1 S, 2 R)$-(-)-2-benzylindan-1-ol $((1 S, 2 R)-2),[\alpha]_{\mathrm{D}}^{20}-11.6(c 0.3$ in $\left.\mathrm{CHCl}_{3}\right)$ : $>99 \%$ ee, $\Delta \varepsilon_{272}-0.22 ; \Delta \varepsilon_{221}-1.3\left(c 6.2 \times 10^{-3} \mathrm{M}\right.$ in EtOH $)$.

Lipase-mediated hydrolysis. Lipase $(60 \mathrm{mg})$ was added to a mixture of the racemic acetate anti-( \pm )-4 $(20 \mathrm{mg}, 0.075$ $\mathrm{mmol}$ ) in $1.5 \mathrm{~mL}$ of solvent (mixture of 1,4-dioxane and buffer $\mathrm{KH}_{2} \mathrm{PO}_{4}: \mathrm{KOH} 0.1 \mathrm{M} \mathrm{pH} \mathrm{7).} \mathrm{The} \mathrm{solution} \mathrm{was} \mathrm{stirred} \mathrm{at} \mathrm{room}$ temperature. The residue obtained upon evaporation of the filtered reaction mixture was chromatographed on a silica gel column and eluted with hexane-ethyl acetate $(95: 5)$. The first eluted fractions provided the unreacted starting material and the last eluted fractions afforded the alcohol derivative $(1 S, 2 R)$-2-benzylindan1-ol $((1 S, 2 R)-2), 93 \% e e,[\alpha]_{\mathrm{D}}^{20}+10.4\left(c 0.1\right.$ in $\left.\mathrm{CHCl}_{3}\right)$. Detailed results are reported in Table 3.

\section{Microorganism cultures and antifungal assays}

The cultures of Botrytis cinerea employed in this work were obtained from grapes from the Domecq vineyard, Jerez de la Frontera, Cádiz, Spain (BcUCA992) and from the Colección Española de Cultivos Tipo (CECT), Facultad de Biología, Universidad de Valencia, Spain (Bc2100).

Antifungal activity was determined by means of a conidial germination assay. The test compound was dissolved in ethanolwater mixtures to give a final compound concentration of 10 $150 \mathrm{mg} \mathrm{L}^{-1}$. Two microlitres of a conidial suspension in water containing about $5 \times 10^{4}$ conidia $/ \mathrm{mL}$ of the $B$. cinerea strains were added to a solution of the test compound $(15 \mu \mathrm{L})$ and PDB (potato dextrose broth) medium $(2 \mu \mathrm{L})$ on ELISA plates. The final ethanol concentration was identical in control and treated cultures. Three replicates were made per compound and the viability of conidia was estimated by measuring their germination just after incubation at $25^{\circ} \mathrm{C}$ for $24 \mathrm{~h}$.

\section{General culture conditions}

Fungi were grown at $25^{\circ} \mathrm{C}$ on a Czapeck-Dox medium $(150 \mathrm{~mL}$ per Roux bottle) on surface culture for 2 days. The substrate dissolved in ethanol was added to each Roux bottle and fermentation continued for a further period of 5 days. The mycelium was filtered and washed with brine and ethyl acetate. The broth was extracted three times with ethyl acetate and the extract dried over anhydrous sodium sulfate. The solvent was then evaporated and the residue was chromatographed first on a silica gel column and then with HPLC with an increasing gradient of ethyl acetate to petroleum ether.

\section{Biotransformation of anti-( \pm )-2-benzylindan-1-ol (anti-( \pm )-2) by Botrytis cinerea 2100}

B. cinerea 2100 was grown as a surface culture in Roux bottles on a Czapeck-Dox medium. The substrate anti-( \pm )-2-benzylindan-1ol (anti-( \pm$)-2)$ dissolved in ethanol was distributed over 17 Roux bottles ( $50 \mathrm{ppm}$ per bottle). After the work-up procedure described above the compound $(R)-(-)-2$-benzylindan-1-one $((R)-3)(60 \mathrm{mg})$ $\left([\alpha]_{\mathrm{D}}^{20}-172.3\left(c 0.1\right.\right.$ in $\left.\left.\mathrm{CHCl}_{3}\right), 75 \% e e\right)$ was isolated. This product was obtained as a colourless oil and its spectroscopic data coincide with those found in the literature. ${ }^{10,17}$ Enantiomeric excess was measured by means of chiral HPLC with $n$-hexane/ $i$-PrOH 9:1

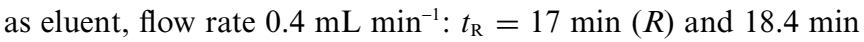
$(S)$.

\section{Biotransformation of anti-( \pm )-2-benzylindan-1-ol (anti-( \pm )-2) by Botrytis cinerea UCA992}

B. cinerea UCA992 was grown as a surface culture in Roux bottles on a Czapeck-Dox medium. The substrate 


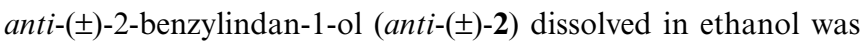
distributed over 17 Roux bottles (100 ppm per bottle). After the work-up procedure described above the following compounds were isolated: recovered (1S,2R)-2-benzylindan-1-ol $((1 S, 2 R)-2)$ (36 mg) $\left([\alpha]_{\mathrm{D}}^{20}-3.5\right.$ (c 2.3 in $\left.\mathrm{CHCl}_{3}\right), 25 \%$ ee), syn-2-benzyl-2,3dihydroxyindan-1-one (5) (4 mg) $\left([\alpha]_{\mathrm{D}}^{20}-10.2\left(c 0.1\right.\right.$ in $\left.\mathrm{CHCl}_{3}\right), 16 \%$ $e e)$, anti-2-benzyl-3-hydroxyindan-1-one (6) (2 mg) (61\% ee), and $(R)$-2-(p-hydroxybenzyl)-7-hydroxyindan-1-one (7) $(5 \mathrm{mg})\left([\alpha]_{\mathrm{D}}^{20}\right.$ -27.6 ( $c 0.1$ in $\mathrm{MeOH}), 81 \% e e$ ).

\section{syn-2-Benzyl-2,3-dihydroxyindan-1-one (5)}

Obtained as a colourless oil; $[\alpha]_{\mathrm{D}}^{20}-10.2\left(c 0.1\right.$ in $\left.\mathrm{CHCl}_{3}\right), 100 \%$ ed, $16 \%$ ee; $v_{\max }($ film $) / \mathrm{cm}^{-1} 3417,2924$ and $1631 ; \delta_{\mathrm{H}}(600 \mathrm{MHz}$; $\left.\mathrm{CDCl}_{3}\right) 3.05$ (2 H, d, J 7.6, H-10), 4.81 (1 H, bs, H-3), $7.25(3 \mathrm{H}$, m, 3Harom), 7.33 (6 H, m, 6Harom); $\delta_{\mathrm{C}}\left(150 \mathrm{MHz} ; \mathrm{CDCl}_{3}\right) 37.2$ (t, C-10), 77.1 (d, C-3), 77.7 (s, C-2), 123.9 (d, Carom), 125.4 (d, Carom), 126.7 (d, Carom), 128.7 (d, 2Carom), 128.9 (d, 2Carom), 129.0 (d, Carom), 129.5 (d, Carom), 139.6 (s, Carom), 139.8 (s, Carom), 143.4 (s, Carom), 214.6 (s, C-1); MS ( $m / z, \%): 254\left(\mathrm{M}^{+}\right.$, 25), 236 (19), 147 (100), 77 (48); m/z HRMS (EI, $70 \mathrm{eV)}$ calcd for $\mathrm{C}_{16} \mathrm{H}_{14} \mathrm{O}_{3}$ : 254.0943; found: $236.0861\left[\mathrm{M}-\mathrm{H}_{2} \mathrm{O}\right]^{+}$. HPLC (nhexane $/ i$-PrOH $95: 5,0.8 \mathrm{~mL} \mathrm{~min}^{-1}$ ): $t_{\mathrm{R}} 16.8 \mathrm{~min}$ (major) and $23.8 \mathrm{~min}$ (minor).

\section{anti-2-Benzyl-3-hydroxyindan-1-one (6)}

Obtained as a colourless oil, 61\% ee, anti/syn 78:22 as determined by ${ }^{1} \mathrm{H}$ NMR spectroscopy. The assignments of product structure were done attending to the spectroscopic data reported in literature. ${ }^{4} \mathrm{HPLC}$ ant $i$-isomer (n-hexane/ $i$-PrOH $9: 1$, $0.6 \mathrm{~mL} \mathrm{~min}^{-1}$ ): $t_{\mathrm{R}} 13.7 \mathrm{~min}$ (major) and $14.4 \mathrm{~min}$ (minor).

\section{(R)-2-(p-Hydroxybenzyl)-7-hydroxyindan-1-one (7)}

Obtained as a yellow oil; $[\alpha]_{\mathrm{D}}^{20}-27.6$ ( $c 0.1$ in $\left.\mathrm{MeOH}\right), 81 \% e e$; $v_{\max }$.(film) $/ \mathrm{cm}^{-1} 3343,2356$ and $1688 ; \delta_{\mathrm{H}}\left(400 \mathrm{MHz} ; \mathrm{CD}_{3} \mathrm{OD}\right) 2.61$ ( $1 \mathrm{H}$, dd, $J 13.8$ and 9.5, H-10a), $2.74(1 \mathrm{H}, \mathrm{dt}, J 16.8$ and 3.0, H-3a), 2.94 (1 H, m, H-2), 3.04 (1 H, dd, $J 16.8$ and 7.4, H-3b), 3.13 ( $1 \mathrm{H}, \mathrm{dd}, J 13.8$ and 4.4, H-10b), 6.67 (2 H, d, $J$ 8.5, H-3', H-5'), 7.03 (1 H, m, H-5), 7.04 (2 H, d, J 8.5, H-2', H-6'), 7.07 (1 H, bd, $J$
8.2, H-6), 7.27 (1 H, bd, $J$ 8.5, H-4); $\delta_{\mathrm{C}}\left(100 \mathrm{MHz}\right.$; $\left.\mathrm{CD}_{3} \mathrm{OD}\right) 32.1$ (t, C-3), 37.2 (t, C-10), 51.2 (d, C-2), 108.9 (d, C-5), 116.2 (d, C-3', C-5') 125.0 (d, C-6), 128.5 (d, C-4), 130.9 (d, C-2', C-6'), 131.5 (s, C-1'), 138.8 (s, C-9), 147.0 (s, C-8), 156.9 (s, C-4'), 158.5 (s, C-7), 211.0 (s, C-1); MS (m/z, \%): 254 (M+ 64), 236 (3), 148 (69), 107 (100), 91 (13), 77 (34); $m / z$ HRMS (EI, $70 \mathrm{eV}$ ) calcd for $\mathrm{C}_{16} \mathrm{H}_{14} \mathrm{O}_{3}$ : 254.0943 [M] ${ }^{+}$; found: 254.0927; HPLC (n-hexane/ $i$-PrOH $97: 3$, $\left.0.5 \mathrm{~mL} \mathrm{~min}^{-1}\right): t_{\mathrm{R}} 30.1 \mathrm{~min}(R)$ and $50.9 \mathrm{~min}(S)$.

\section{References}

1 J. R. Smith, K. Verhoeff and W. R. Jarvis, in The Biology of Botrytis, ed. Academic Press, London, 1980, pp. 153-175.

2 T. Stamb, Annu. Rev. Phytopathol., 1991, 29, 421.

3 T. Kokubun, J. B. Harborne and J. Eagles, Phytochemistry, 1994, 35, 331.

4 J. Petrignet, T. Roisnel and R. Grée, Chem.-Eur. J., 2007, 13, 7374.

5 A. J. Bustillo, J. Aleu, R. Hernández-Galán and I. G. Collado, Tetrahedron: Asymmetry, 2002, 13, 1681-1686.

6 R. Pezet, V. Pont and K. Hoang-van, Physiol. Mol. Plant Pathol., 1991, 39(6), 441-450.

7 A. E. Osbourn, Fungal Genet. Biol., 1999, 26, 163-168.

8 J. Aleu, G. Fronza, C. Fuganti, V. Perozzo and S. Serra, Tetrahedron: Asymmetry, 1998, 9, 1589-1596.

9 (a) G. Fronza, C. Fuganti, P. Grasselli and A. Mele, J. Org. Chem., 1991, 56, 6019; (b) P. Florey, A. J. Smallridge, A. Ten and M. A. Trewhella, Org. Lett., 1999, 1, 1879; (c) J. Bálint, G. Egri, A. Kolbert, C. Dianóczky, E. Fogassy, L. Novák and L. Poppe, Tetrahedron: Asymmetry, 1999, 10, 4017.

10 A. Martínez, M. Fernández, J. Estévez, R. Estévez and L. Castedo, Tetrahedron, 2005, 61, 485-492.

11 (a) G. Snatzke and P. C. Ho, Tetrahedron, 1971, 27, 3645-3653; (b) H. E. Smith and L. P. Fontana, J. Org. Chem., 1991, 56, 432-435.

12 R. J. Lorentzen, J. H. Brewster and H. E. Smith, J. Am. Chem. Soc., 1992, 114, 2181-2187.

13 (a) W.-R. Shieh, A. S. Golapan and C. J. Sih, J. Am. Chem. Soc., 1985, 107, 2993; (b) K. Nakamura, Y. Kawai, N. Nakajima and A. Ohno, J. Org. Chem., 1991, 56, 4778.

14 J.-N. Cui, T. Ema, T. Sakai and M. Utaka, Tetrahedron: Asymmetry, 1998, 9, 2681.

15 G. De Gonzalo, R. Brieva, V. M. Sánchez, M. Bayod and V. Gotor, J. Org. Chem., 2001, 66, 8947-8953.

16 I. Prost, S. Dhondt, G. Rothe, J. Vicente, M. J. Rodriguez, N. Kift, F. Carbonne, G. Griffiths, S. Rosahl, C. Castresana, M. Hamberg and J. Fournier, Plant Physiol., 2005, 139, 1902-1913.

17 J. M. Lamarche, J. Vebrel and B. Laude, Spectrochim. Acta, Part A, 1979, 35, 673-677. 